\title{
Efeito do histórico reprodutivo da vaca sobre o desempenho da progênie
}

\author{
Effect of the cow's reproductive history on the progeny performance \\ Efecto de la historia reproductiva de la vaca sobre el desempeño de la progenie
}

Recebido: 09/01/2021 | Revisado: 13/01/2021 | Aceito: 16/01/2021 | Publicado: 19/01/2021

John Lenon Klein
ORCID: https://orcid.org/0000-0001-8337-4152
Universidade Federal de Santa Maria, Brasil
E-mail: johnlenonklein @ gmail.com
Ivan Luiz Brondani
ORCID: https://orcid.org/0000-0002-6526-3042
Universidade Federal de Santa Maria, Brasil
E-mail: ivanbrondani @ gmail.com
Dari Celestino Alves Filho
ORCID: https://orcid.org/0000-0003-2559-7504
Universidade Federal de Santa Maria, Brasil
E-mail: darialvesfilho@ @otmail.com
Sander Martinho Adams
ORCID: https://orcid.org/0000-0003-4895-8237
Universidade Federal de Santa Maria, Brasil
E-mail: sander.adams@ @otmail.com
Joziane Michelon Cocco
ORCID: https://orcid.org/0000-0001-6617-3076
Universidade Federal de Santa Maria, Brasil
E-mail: jozimichelon@ @otmail.com
Fabiana Moro Maidana
ORCID: https://orcid.org/0000-0002-9946-5355
Universidade Federal de Santa Maria, Brasil
E-mail: f96033512@ gmail.com
Ricardo Gonçalves Gindri
ORCID: https://orcid.org/0000-0003-3674-8400
Universidade Federal de Santa Maria, Brasil
E-mail: ricardo.gindri@ @ahoo.com.br
Dieison Pansiera Antunes
ORCID: https://orcid.org/0000-0002-9672-8455
Universidade Federal de Santa Maria, Brasil
E-mail: diesonpansiera@ @otmail.com

\section{Resumo}

A condição nutricional e fisiológica da vaca durante a gestação tem sido associada com a formação fetal e desempenho futuro da progênie. O objetivo do trabalho foi avaliar os efeitos do histórico da vaca gestante sobre o desempenho da progênie. Foram utilizadas 343 vacas de corte Charolês e Nelore, sendo divididas conforme o histórico reprodutivo: vacas prenhas que repetiram prenhez $(\mathrm{P})$; vacas vazias que emprenharam (V). Os dados foram coletados durante 5 anos no rebanho experimental. Vacas $\mathrm{V}$ apresentaram maior escore de condição corporal (ECC) (2,83 vs 3,05 pontos) e peso corporal ao final da estação reprodutiva $(462,72 v s 478,82 \mathrm{~kg}$ ), além de menor ECC ao parto (2,58 vs 2,64 pontos) e maior perda de peso durante a gestação $(-35,17 v s-13,34 \mathrm{~kg})$ em comparação às vacas $\mathrm{P}$. $\mathrm{O}$ peso ajustado aos 205 dias de idade foi maior na progênie de vacas $\mathrm{P}(140,54 v s 139,35 \mathrm{~kg})$, sem efeitos aos $365 \mathrm{e}$ 540 dias $(\mathrm{P}>0,05)$. O desempenho aos 7 meses de idade foi maior na progênie de vacas $\mathrm{P}(0,517$ vs $0,502 \mathrm{~kg} / \mathrm{dia})$, enquanto que a progênie de vacas $\mathrm{V}$ foi superior aos $12 \mathrm{e}$ aos 18 meses de idade, com valores respectivamente de 0,558 vs 0,397 e 0,379 vs $0,351 \mathrm{~kg} / \mathrm{dia}$. Bezerros de vacas $\mathrm{P}$ apresentaram maior valor de Kleiber aos 7 meses, enquanto que a progênie de vacas $\mathrm{V}$ foi mais eficiente aos 12 meses. $\mathrm{O}$ histórico reprodutivo da vaca influencia o desempenho da progênie, onde vacas vazias produzem bezerros com maior potencial produtivo na vida adulta.

Palavras-chave: Escore corporal; Ganho de peso; Nutrição; Programação fetal.

\begin{abstract}
The nutritional and physiological condition of the cow during pregnancy has been associated with fetal formation and future progeny performance. The objective of the work was to evaluate the effects of the history of the pregnant cow on the progeny performance. 343 Charolais and Nellore beef cows were used, divided according to reproductive history: pregnant cows that repeated pregnancy $(\mathrm{P})$; empty cows that have impregnated $(\mathrm{V})$. The data were collected during 5 years in the experimental herd. V cows had a higher body condition score (BCS) (2.83 vs 3.05 points) and body weight at the end of the reproductive season (462.72 vs $478.82 \mathrm{~kg}$ ), in addition to a lower BCS at calving (2.58 vs 2.64 points) and greater weight loss during pregnancy $(-35.17$ vs $-13.34 \mathrm{~kg})$ compared to $\mathrm{P}$ cows. The weight
\end{abstract}


adjusted at 205 days of age was higher in the progeny of P cows (140.54 vs $139.35 \mathrm{~kg}$ ), with no effects at 365 and 540 days $(\mathrm{P}>0.05)$. The performance at 7 months of age was higher in the progeny of $\mathrm{P}$ cows $(0.517 \mathrm{vs} 0.502 \mathrm{~kg} / \mathrm{day})$, while the progeny of $\mathrm{V}$ cows was superior at 12 and 18 months of age, with values respectively of $0.558 v s 0.397$ and 0.397 vs $0.351 \mathrm{~kg} / \mathrm{day}$. Calves of $\mathrm{P}$ cows showed higher Kleiber value at 7 months, while the progeny of $\mathrm{V}$ cows was more efficient at 12 months. The reproductive history of the cow influences the performance of the progeny, where empty cows produce calves with greater productive potential in adulthood.

Keywords: Body score; Fetal programming; Weight gain; Nutrition.

\section{Resumen}

La condición nutricional y fisiológica de la vaca durante el embarazo se ha asociado con la formación fetal y el desempeño futuro de la progenie. El objetivo del trabajo fue evaluar los efectos de la historia de la vaca preñada sobre el desempeño de la progenie. Se utilizaron 343 vacas de carne Charolais y Nellore, divididas según antecedentes reproductivos: vacas preñadas que preñez repetida $(\mathrm{P})$; vacas vacías que han preñado $(\mathrm{V})$. Los datos fueron recolectados durante 5 años en el rebaño experimental. Las vacas V tuvieron un puntaje de condición corporal (PCC) más alto (2.83 vs 3.05 puntos) y peso corporal al final de la temporada reproductiva (462.72 vs $478.82 \mathrm{~kg})$, además de un PCC más bajo al parto (2.58 vs 2.64 puntos) y mayor pérdida de peso durante la gestación $(-35.17 \mathrm{vs}-13.34 \mathrm{~kg})$ en comparación con las vacas P. El peso ajustado a los 205 días de edad fue mayor en la progenie de las vacas P (140, 54 vs $139,35 \mathrm{~kg}$ ), sin efectos a los 365 y 540 días $(\mathrm{P}>0.05)$. El rendimiento a los 7 meses de edad fue mayor en la progenie de las vacas $\mathrm{P}$ (0.517 vs $0.502 \mathrm{~kg} /$ día), mientras que la progenie de las vacas $\mathrm{V}$ fue superior a los $12 \mathrm{y} 18$ meses de edad, con valores de 0.558 vs 0.397 y 0.397 vs $0,351 \mathrm{~kg} /$ día. Los terneros de vacas P mostraron mayor valor de Kleiber a los 7 meses, mientras que la progenie de vacas $\mathrm{V}$ fue más eficiente a los 12 meses. La historia reproductiva de la vaca influye en el desempeño de la progenie, donde las vacas vacías producen terneros con mayor potencial productivo en la edad adulta.

Palabras clave: Aumento de peso; Nutrición; Programación fetal; Puntuación corporal.

\section{Introdução}

Atualmente, o Brasil possui o maior rebanho de bovinos do mundo com aproximadamente 200 milhões de cabeças (Anualpec, 2019), aspecto que garante a competitividade do país frente às potências mundiais neste setor produtivo. Segundo os levantamentos da Associação Brasileira das Indústrias Exportadoras de Carnes (Abiec, 2020), o Brasil é o maior exportador mundial de carne bovina, com aproximadamente 2,5 milhões de toneladas de equivalente carcaça.

Melhorar os índices Zootécnicos na produção de bovinos de corte é um desafio para atingir a máxima eficiência produtiva. A literatura atual vem investigando constantemente os efeitos do status nutricional da vaca durante a gestação sobre a formação fetal e o desempenho da progênie na vida adulta (Du et al., 2013), conceito conhecido como "Programação Fetal". Dentre as demandas nutricionais da vaca gestante que competem com o crescimento fetal, podemos destacar as exigências para mantença e crescimento corporal, assim como para manutenção da lactação no início da gestação. Gonzales-Recio et al. (2012) observaram que novilhas nascidas de vacas que produziam leite durante a gestação foram metabolicamente menos eficientes, produziram 53 litros a menos de leite e morreram 16 dias antes em relação às filhas de vacas que não produziram leite.

A forma mais usual de mensurar o status nutricional das vacas é através da avaliação do escore de condição corporal (ECC). Os efeitos da variação no ECC gestantes foram avaliados por Marques et al. (2016). Estes autores observaram que o ganho de ECC no segundo ou terceiro trimestre de gestação melhorou o desempenho da progênie ao desmame. Desta forma, as reservas corporais da vaca gestante podem influenciar a distribuição de nutrientes ao feto em formação. Bohnert et al. (2013) observaram que vacas com maiores reservas corporais ao parto produziram terneiros mais pesados ao nascimento (38,8 vs 41,4 $\mathrm{kg}$ ), porém, sem alteração no desempenho da progênie na vida adulta. Diante dos fatores que podem alterar as demandas nutricionais da vaca durante a gestação e consequentemente a formação fetal, o objetivo do presente estudo foi avaliar os efeitos do histórico reprodutivo da vaca sobre o desempenho da progênie até os 18 meses de idade. 


\section{Metodologia}

Os animais utilizados no presente trabalho são oriundos de outro projeto de pesquisa intitulado "Cruzamento em bovinos de corte envolvendo as raças Charolês e Nelore”, com registro nº 3781220520 no Comitê de Ética de Uso de Animais na Universidade Federal de Santa Maria, RS - Brasil.

\section{Animais e fatores de estudo}

Foram utilizadas 343 vacas de corte pertencentes ao cruzamento rotativo contínuo entre as raças Charolês e Nelore (Tabela 1). As vacas possuíam idade média variando entre 5 e 12 anos, com intuito de excluir as novilhas e primíparas do banco de dados. As vacas foram classificadas conforme o histórico reprodutivo do ano anterior, em: 259 vacas que estavam prenhas e repetiram prenhez (P); 84 vacas que estavam vazias e ficaram prenhas (V). Assim, no ano avaliativo, foram utilizadas somente as vacas prenhas do rebanho, podendo uma mesma fêmea pertencer aos dois tratamentos durante os 5 anos de avaliações (2013 a 2017), de acordo com seu histórico reprodutivo.

Tabela 1 - Medidas descritivas das vacas utilizadas no estudo.

\begin{tabular}{cccc}
\hline \% sangue Zebuíno & Geração do cruzamento & Prenha (n) & Vazia (n) \\
\hline 0 & - & 13 & 3 \\
31,25 & 4 & 41 & 14 \\
34,38 & 5 & 50 & 15 \\
65,63 & 5 & 87 & 30 \\
68,75 & 4 & 41 & 8 \\
100 & - & 27 & 14 \\
\hline
\end{tabular}

Fonte: arquivo de dados do Laboratório de Bovinocultura de Corte da UFSM.

A fazenda experimental é composta pelo ciclo completo de produção de bovinos de corte, onde as vacas permanecem em pastagem natural durante a gestação e lactação. A pastagem nativa era composta na maior parte pela espécie estival de origem Africana denominada capim- annoni (Eragrostis plana Ness), e por demais espécies de gramíneas de estação quente Paspalum notatum, Axonupus affinis e Desmodium incanum (Silveira et al., 2014). A taxa de lotação utilizada nos piquetes é de $0,8 \mathrm{UA}$ por hectare, aproximadamente $360 \mathrm{~kg}$ de peso corporal. Nos piquetes, é ofertado sal mineral 80P ( $80 \mathrm{~g}$ de fósforo por kg de sal) ad libitum aos animais.

A parição das vacas ocorre entre 15 de setembro e 15 de dezembro, totalizando 90 dias. Após o parto, o conjunto vaca e bezerro foram levados ao centro de manejo para os primeiros cuidados com o recém-nascido, e posteriormente realocados em piquete com patagem natural até o desmame. $\mathrm{O}$ desmame dos bezerros foi realizado aos 75 dias de idade, estratégia conhecida como desmame precoce. Após o desmame, as vacas foram introduzidas na reprodução,composta por 45 dias de inseminação artificial seguidos de 45 dias de repasse com os touros numa relação de 1:25 vacas.

Os bezerro permaneceram sete dias na mangueira e foram posteriormente realocados em pastagem de Tifton-85 (cynodon spp), recebendo $1 \%$ do peso vivo de suplementação concentrada até o período de inverno. O suplemento dos bezerros apresentou variação anual na composição, com 20 a 22\% de proteína bruta e 80 a $85 \%$ de nutrientes digestíveis totais.

Posteriormente, o crescimento dos bezerros ocorreu exclusivamente em pastagem consorciada de Aveia Preta + Azevém (Avena strigosa + Lolium multiflorum) no período de inverno, seguido de pastagem tropical composta de milheto 
(Pennisetum glaucum) até o outono subsequente. Durante todo o período de crescimento, sal mineral de livre acesso era ofertado aos animais.

\section{Medidas de desempenho}

O desempenho das vacas foi avaliado pelas pesagens no final da estação reprodutiva, assim como no dia da parição. A variação de peso corporal (PC) das vacas durante a gestação foi calculada pela diferença de peso entre as duas pesagens consecutivas. Nas mesmas ocasiões das pesagens, com o auxílio de dois avaliadores treinados, foi mensurado o escore de condição corporal das vacas (ECC), utilizando a escala de 1 a 5 descrita por Torres et al. (2015).

O desempenho da progênie foi avaliado a partir da variação do peso corporal ao longo da vida pós-natal. Os bezerros foram pesados ao nascimento, e posteriormente aos 7, 12 e 18 meses de idade. Para reduzir a variação da idade, o peso dos bezerros foi ajustado para os 205, 365 e 540 dias de vida. O ganho médio diário (GMD) foi calculado através da diferença de peso pelo quociente do intervalo de dias entre as pesagens dos animais.

Para complementar as medidas de desempenho dos bezerros, foi calculada a relação de Kleiber (RK), através da seguinte fórmula descrita por Klein et al. (2018): RK = GMD/PVM, onde GMD é o ganho médio diário em g/dia e PVM a média em kg do peso vivo metabólico do período $\left(\mathrm{PVM}^{0,75}\right)$. A RK foi medida em g de ganho de peso por unidade de peso metabólico (g/UTM).

\section{Análises estatísticas}

Os dados foram submetidos ao teste de rstudent para detectar a presença de outliers. Foram eliminados os valores fora de \pm 2 desvios padrões da média. Posteriormente, foi realizado o teste de normalidade dos resíduos utilizando o teste de Shapiro-Wilk a 5\% de significância. Fora realizadas transformações nas seguintes variáveis de estudo: GMD12M (Sqrt); GMDtotal, PV, pajust205, pajust365 e pajust540 (Log). Os dados foram submetidos a análise de variância pelo teste F, através do procedimento PROC GLM, e quando constatada significância, foi realizada a comparação de médias utilizando o teste de Tukey a 5\% de significância. As análises estatísticas foram realizadas através do pacote estatístico $\mathrm{SAS}^{\circledR}$ Studio University Edition, utilizando o seguinte modelo matemático:

$$
\mathrm{Y}_{\mathrm{ijklmn}}=\mu+\mathrm{H}_{i}+\mathrm{S}_{j}+\left(\mathrm{H}^{*} \mathrm{~S}\right)_{k}+\mathrm{N}_{l}+\mathrm{I}_{m}+\mathrm{A}_{n}+\varepsilon_{i j k l m n}
$$

Onde: $\mu$ é a média de todas as obesrvações; $\mathrm{H}_{i}$ é o efeito do histórico reprodutivo da vaca; $\mathrm{S}_{j}$ é o efeito do sexo do bezerro; $(\mathrm{H} * \mathrm{~S})_{k}$ é a interação entre os fatores de estudo; $\mathrm{N}_{l}$ é o efeito da co-variável da percentagem de sangue zebuíno da vaca; $\mathrm{I}_{m}$ é o efeito da covariável idade da vaca; $\mathrm{A}_{n}$ é o efeito da co-variável do ano de produção e $\varepsilon_{i j k l m n}$ é o efeito do erro experimental.

\section{Resultados}

Não houve interação entre o histórico reprodutivo da vaca e o sexo sobre o desempenho dos bezerros até os 18 meses de idade. Logo, os resultados serão apresentados separadamente ao longo do texto. As medidas de desempenho das vacas de corte não foram influenciadas pelo sexo do bezerro $(\mathrm{P}>0,05)$, sendo observado uma mobilização de reservas corporais e consequentemente perda de peso em todos os grupos de estudo (Tabela 2). 
Tabela 2 - Desempenho das vacas gestantes com diferentes históricos reprodutivos.

\begin{tabular}{|c|c|c|c|c|c|c|c|c|c|}
\hline \multirow{2}{*}{ Variáveis } & \multicolumn{2}{|c|}{ Prenha } & \multicolumn{2}{|c|}{ Vazia } & \multirow{2}{*}{$\begin{array}{l}\text { Std } \\
\text { dev }\end{array}$} & \multirow{2}{*}{$\mathrm{CV}, \%$} & \multicolumn{3}{|c|}{$\mathrm{P}$ - valor } \\
\hline & Macho & Fêmea & Macho & Fêmea & & & Trat $^{1}$ & Sexo & Trat*Sexo \\
\hline Escore $\mathrm{FER}^{2}$, pontos & 2,80 & 2,86 & 3,02 & 3,08 & 0,24 & 7,67 & $<0,0001$ & 0,0912 & 0,8862 \\
\hline ECC ao parto, pontos & 2,63 & 2,65 & 2,58 & 2,58 & 0,31 & 11,72 & 0,0337 & 0,6275 & 0,7899 \\
\hline Peso $\mathrm{FER}^{2}, \mathrm{~kg}$ & 459,66 & 465,79 & 485,12 & 472,53 & 58,40 & 12,03 & 0,0041 & 0,6545 & 0,1368 \\
\hline Peso vaca ao parto, $\mathrm{kg}$ & 447,97 & 452,13 & 442,63 & 442,35 & 62,70 & 16,74 & 0,2459 & 0,6843 & 0,5204 \\
\hline Variação de peso, kg & $-11,18$ & $-15,51$ & $-41,77$ & $-28,58$ & 40,81 & 100,38 & $<0,0001$ & 0,2828 & 0,1320 \\
\hline
\end{tabular}

Os valores são as médias preditas pelo teste de tukey a 5\% de probabilidade. Valores de $\mathrm{P}<0,05$ indicam diferenças para os fatores de estudo.

${ }^{1}$ Histórico reprodutivo da vaca (prenha $v s$ vazia); ${ }^{2}$ Final da estação reprodutiva.

Fonte: arquivo de dados do Laboratório de Bovinocultura de Corte da UFSM.

Vacas vazias (V) apresentaram maior escore de condição corporal (ECC) $(2,83$ vs 3,05 pontos, P < 0,0001) e peso corporal (PC) ao final da estação reprodutiva $(462,72$ vs 478,82 kg, P =0,0041), em relação às vacas prenhas (P) (Tabela 2). Porém, vacas V apresentaram menor ECC ao parto em relação às vacas $\mathrm{P}(2,58$ vs 2,64 pontos, $\mathrm{P}=0,0337)$. $\mathrm{O}$ PC das vacas ao parto não foi influenciado pelo histórico reprodutivo $(446,27 \mathrm{~kg}, \mathrm{P}>0,05)$, porém, vacas $\mathrm{V}$ perderam mais peso durante a gestação em comparação às vacas $\mathrm{P}$ no mesmo período $(-35,17$ vs $-13,34 \mathrm{~kg}, \mathrm{P}<0,0001)$.

O desempenho da progênie está apresentado na Tabela 3. Os machos apresentaram maiores pesos ao nascer e ajustados para os 205, 365 e 540 dias de idade ( $\mathrm{P}<0,05)$, com superioridade de 1,95; 9,82; 23,36 e 31,52 kg de peso corporal nas respectivas idades. Do mesmo modo, os machos apresentaram maior ganho médio diário (GMD) aos 7 (0,535 vs 0,0484 $\mathrm{kg} / \mathrm{dia})$ e aos 18 meses (0,390 vs 0,339 kg/dia) quando comparados ao desempenho das fêmeas.

O desempenho da progênie também foi influenciado pelo histórico reprodutivo da vaca (Tabela 3). O peso ajustado aos 205 dias de idade foi maior na progênie de vacas $\mathrm{P}(\mathrm{P}=0,0241)$ em relação aos bezerros de vacas $\mathrm{V}(140,54$ vs $139,35 \mathrm{~kg})$. Os pesos dos bezerros aos 365 e 540 dias não foram influenciados pelo histórico da vaca (P > 0,05). O GMD da progênie apresentou comportamento distinto entre as idades avaliadas. O desempenho aos 7 meses de idade foi maior na progênie de vacas $\mathrm{P}$ em relação aos filhos de vacas $\mathrm{V}(0,517$ vs 0,502 kg/dia, $\mathrm{P}=0,0214)$. Porém, o GMD aos 12 e aos 18 meses de idade foi maior na progênie de vacas $\mathrm{V}$ em relação às vacas $\mathrm{P}$, com valores respectivamente de $0,558 v s 0,397 \mathrm{~kg} / \mathrm{dia}(\mathrm{P}=0,0214) \mathrm{e}$ 0,379 vs $0,351 \mathrm{~kg} / \mathrm{dia}(\mathrm{P}=0,0489)$.

Não houve efeitos do sexo dos bezerros sobre a eficiência produtiva dos bezerros medida pela relação de Kleiber (P > 0,05). Porém, a eficiência produtiva dos bezerros foi influenciada pelo histórico reprodutivo da vaca (Figura 1). Bezerros filhos de vacas $\mathrm{P}$ foram mais eficientes até aos 7 meses $(\mathrm{P}<0,0001)$, produzindo $0,7 \mathrm{~g} / \mathrm{UTM}$ a mais que filhos de vacas $\mathrm{V}$ nos primeiros meses de vida. Contudo, a progênie de vacas $\mathrm{V}$ foi mais eficiente aos 12 meses $(\mathrm{P}=0,0383)$, com produção de 0,8 g/UTM a mais em relação aos bezerros de vacas P. Não houve efeito do histórico da vaca na relação de Kleiber aos 18 meses de idade $(\mathrm{P}=0,1370)$, com produção média de $1,97 \mathrm{~g} / \mathrm{UTM}$ no período. 
Tabela 3 - Desempenho dos bezerros filhos de vacas com diferentes históricos reprodutivos.

\begin{tabular}{|c|c|c|c|c|c|c|c|c|c|}
\hline \multirow{2}{*}{ Variáveis } & \multicolumn{2}{|c|}{ Prenha } & \multicolumn{2}{|c|}{ Vazia } & \multirow{2}{*}{$\begin{array}{l}\text { Std } \\
\text { dev }\end{array}$} & \multirow{2}{*}{$\begin{array}{c}\mathrm{CV} \\
\%\end{array}$} & \multicolumn{3}{|c|}{$\mathrm{P}$ - valor } \\
\hline & Macho & Fêmea & Macho & Fêmea & & & Trat $^{1}$ & Sexo & Trat*Sexo \\
\hline Peso ao nascer, $\mathrm{kg}$ & 35,34 & 32,90 & 35,24 & 33,77 & 6,07 & 16,74 & 0,3588 & 0,0326 & 0,3352 \\
\hline P. ajustado 205 dias, $\mathrm{kg}$ & 145,34 & 135,74 & 144,36 & 134,31 & 34,77 & 20,63 & 0,0241 & 0,0379 & 0,7205 \\
\hline P. ajustado 365 dias, $\mathrm{kg}$ & 213,84 & 193,58 & 240,25 & 213,77 & 54,62 & 18,19 & 0,9544 & 0,0017 & 0,5021 \\
\hline P. ajustado 540 dias, $\mathrm{kg}$ & 280,45 & 245,62 & 306,12 & 277,89 & 77,54 & 18,00 & 0,4017 & 0,0003 & 0,9121 \\
\hline GMD 7 meses, kg/dia & 0,535 & 0,500 & 0,536 & 0,468 & 0,16 & 27,95 & 0,0006 & 0,0234 & 0,2898 \\
\hline GMD 12 meses, kg/dia & 0,429 & 0,366 & 0,593 & 0,524 & 0,24 & 44,34 & 0,0214 & 0,1004 & 0,8070 \\
\hline GMD 18 meses, $\mathrm{kg} / \mathrm{dia}$ & 0,389 & 0,313 & 0,392 & 0,366 & 0,20 & 42,95 & 0,0161 & 0,0489 & 0,4598 \\
\hline
\end{tabular}

Os valores são as médias preditas pelo teste de tukey a 5\% de probabilidade. Valores de $\mathrm{P}<0,05$ indicam diferenças para os fatores de estudo.

${ }^{1}$ Histórico reprodutivo da vaca (prenha $v s$ vazia).

Fonte: arquivo de dados do Laboratório de Bovinocultura de Corte da UFSM.

Figura 1 - Efeito do histórico reprodutivo das vacas sobre a eficiência produtiva da progênie até os 18 meses de idade. O * indica diferença a $5 \%$ de probabilidade $(\mathrm{P}<0,05)$.

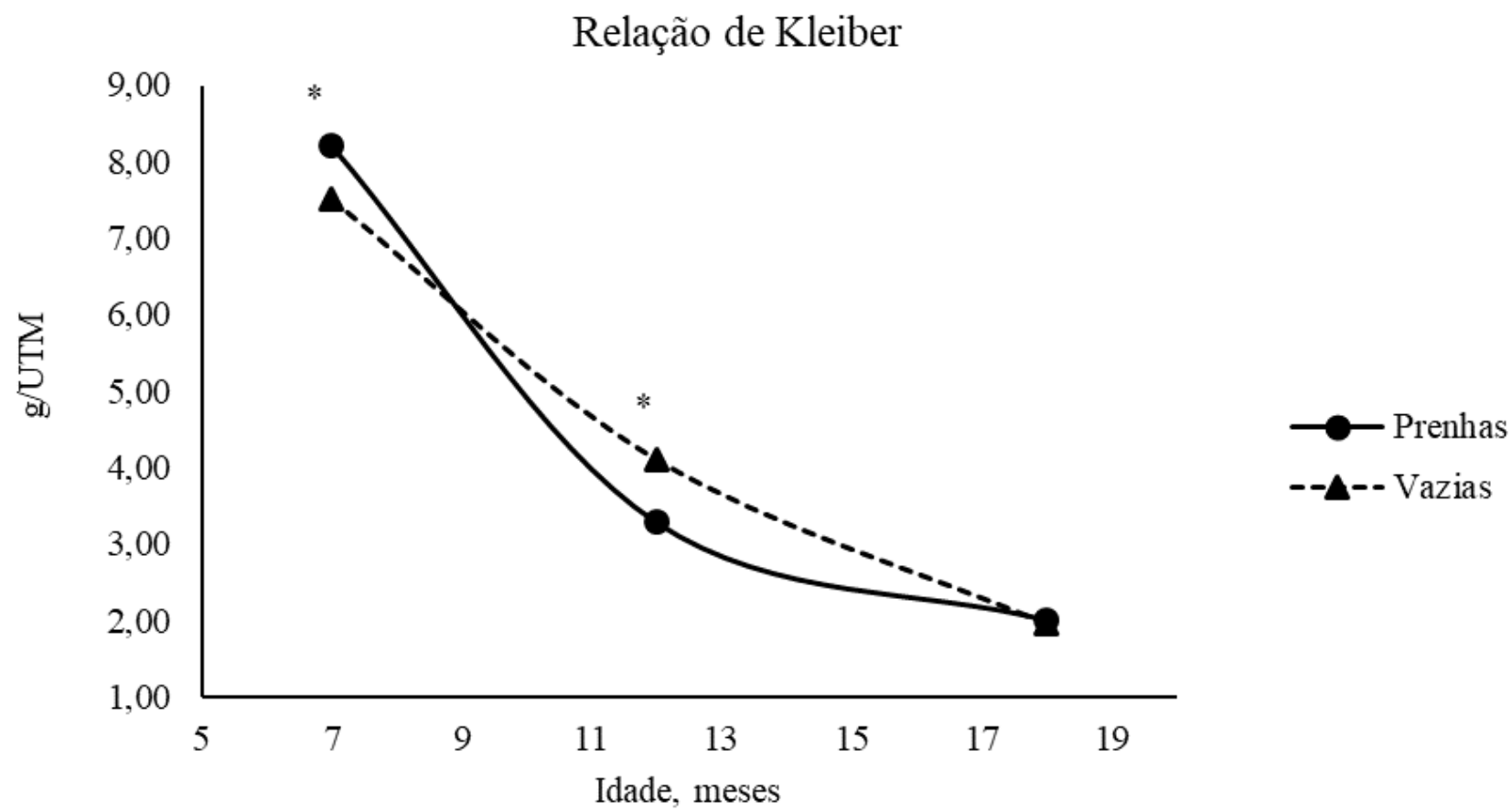

Fonte: arquivo de dados do Laboratório de Bovinocultura de Corte da UFSM.

\section{Discussão}

Em geral, machos apresentam desempenho superior às fêmeas quando mantidos em um mesmo sistema produtivo. Nossos resultados apontam que machos foram respectivamente $6 \%$ mais pesados que as fêmeas ao nascer, com a superioridade aumentado para $11 \%$ até os 540 dias de idade (Tabela 3). Nossos resultados corroboram com Taylor et al. (2016), os quais 
obtiveram machos mais pesados tanto ao nascimento como aos 205 dias de idade (10 e 6\%, respectivamente). Mesmo assim, alguns resultados obtidos na literatura são contraditórios. Trabalhando com diferentes níveis nutricionais no final da gestação, LeMaster et al. (2017) observaram superioridade no peso corporal dos machos em relação às fêmeas após os 30 dias de idade até o desmame dos bezerros, com valores aproximadamente $8 \%$ superiores. Fornecendo níveis alto e baixo de proteína no final da gestação, Maresca et al. (2018) observaram maior peso dos bezerros aos 45 dias de idade (8\%), sendo esta diferença inexistente nas demais idades dos bezerros. Em nosso estudo, o maior desenvolvimento dos machos não aumentou o desgaste das vacas durante a gestação (Tabela 2).

O desempenho das vacas durante a gestação foi influenciado pelo histórico reprodutivo, sendo as maiores perdas de peso e condição corporal nas vazias. Webb et al. (2019) explicam que a mobilização de reservas corporais das vacas durante a gestação ocorre para manter adequada a oferta de nutrientes ao feto em condições moderadas de restrições nutricionais. Segundo Bauman e Currie (1980), a vaca possui mecanismos homeorréicos que regulam a distribuição dos nutrientes no organismo, sendo a gestação uma prioridade. Camacho et al. (2018) estudaram os efeitos da restrição alimentar para vacas de corte nos terços iniciais de gestação, e destacam a capacidade de adaptação das vacas multíparas às condições adversas de oferta de nutrientes, bem como a resiliência da fêmea em suprir as demandas fetais.

A maior mobilização das reservas corporais das vacas $\mathrm{V}$ pode ter melhorado a formação fetal, uma vez que a progênie apresentou maior desempenho após os 7 meses de idade (Tabela 3). Nossa hipótese se baseia no fato das vacas estarem nas mesmas condições de meio, indicando que a maior perda de ECC das vacas $\mathrm{V}$ pode ter favorecido a drenagem de nutrientes para a placenta. Camacho et al. (2018) estudaram os efeitos da restrição alimentar para vacas de corte nos terços iniciais de gestação, e destacam a capacidade de adaptação das vacas multíparas às condições adversas de oferta de nutrientes, bem como a resiliência da fêmea em suprir as demandas fetais. Mohrhauser et al. (2015) complementam que vacas adultas possuem também maiores reservas corporais para atender as demandas fetais, sendo menos sensíveis à falta de nutrientes durante a gestação.

A maior resiliência das vacas $\mathrm{V}$ pela formação fetal pode ter favorecido a formação do músculo esquelético, uma vez que esse tecido possui baixa prioridade nutricional no organismo fetal em relação aos órgãos vitais. Long et al. (2009) observaram maior peso relativo do coração e cérebro aos 125 dias de gestação em fetos de mães submetidas à restrição alimentar em relação aos oriundos de vacas melhor nutridas, indicando que o desenvolvimento do músculo esquelético possui menor prioridade em condições de baixa oferta de nutrientes. Assim, o maior desempenho da progênie de vacas $\mathrm{V}$ pode estar relacionado à maior formação de fibras musculares durante a gestação (Du et al., 2010), fator que favorece o crescimento dos bezerros após o parto. Caso houver baixo número de fibras musculares formadas no período fetal, o crescimento muscular será limitado, uma vez que as fibras musculares não podem exceder o tamanho que possibilite a troca eficiente de nutrientes e metabólitos (Du et al., 2013).

De qualquer maneira, os bezerros de vacas $\mathrm{P}$ foram mais eficientes até os 7 meses de idade, enquanto que a progênie de vacas $\mathrm{V}$ foram mais eficientes após esse período (Figura 1). Além do tecido muscular esquelético, a nutrição materna durante a gestação pode influenciar os processos de formação e maturação dos órgãos e sistemas corporais, afetando consequentemente a função fisiológica dos mesmos (Reynolds et al., 2019). Os mesmos autores afirmam que estas mudanças estruturais e funcionais dos órgãos servem para permitir uma rápida adaptação do feto em desenvolvimento à pressão de seleção ambiental uterina. A restrição de nutrientes para o feto durante a gestação precoce ou média pode afetar negativamente o desenvolvimento do pâncreas fetal (McCarty et al., 2020). Em complemento, Maresca et al. (2018) observaram que bezerros nascidos de vacas com baixa ingestão de proteína durante a metade final de gestação eram hiperglicêmicos durante os primeiros 60 dias de vida, aspecto que limita o desempenho destes animais em sistemas mais intensivos de produção. 
A oscilação nas curvas de desempenho entre as progênie de vacas $\mathrm{P}$ e $\mathrm{V}$ pode ser explicada pela teoria do crescimento fetal é apresentada por Webb et al. (2019), os quais descrevem que a desnutrição ou a restrição alimentar durante a gestação acaba produzindo um fenótipo que possui maiores habilidades adaptativas quando expostos à ambientes desfavoráveis na vida adulta. Nesse contexto, várias hipóteses sobre programação fetal estão sem conclusões concretas e necessitam maiores esclarecimentos futuros, sendo possível produzir tanto uma progênie com alto potencial de crescimento e ganho de peso corporal, como uma progênie com maior capacidade adaptativa para aproveitar os ganhos compensatórios na vida adulta.

\section{Conclusão}

A variação de peso e escore de condição corporal não varia entre as vacas que gestaram machos ou fêmeas. Porém, machos são mais pesados que fêmeas após o parto até os 540 dias de idade.

Vacas vazias apresentam maior perda de peso corporal durante a gestação e menor escore de condição corporal ao parto em relação às vacas Prenhas.

A progênie de vacas Prenhas apresenta maior ganho de peso corporal, maior eficiência de Kleiber e é mais pesada aos 205 dias de idade em relação à progênie de vacas Vazias. Porém, a progênie de vacas Vazias apresenta maior desempenho aos 365 e 540 dias de idade.

\section{Referências}

Associação Brasileira de Indústrias Exportadoras de Carne (2020). Perfil da Pecuária no Brasil, Brasil.

Anuário Brasileiro da Pecuária (2019). Instituto FNP e Agra FNP Pesquisas LTDA, São Paulo, Brasil.

Bauman, D. E., \& Currie, B. (1980). Partitioning of nutrients during pregnancy and lactation: a review of mechanisms involving homeostasis e homeorhesis. Journal of Dairy Science, 63(9), 1514-1529.

Bohnert, D. W., Stalker, L. A., Mills, R. R., Nyman, A., Falck, S. J., \& Cooke, R. F. (2013). Late gestation suplementation of beff cows differing in body condition score: Effects on cow and calf performance. Journal of Animal Science, 91(11), 5485-5491.

Camacho, L. E., Lemley, C. O., Dorsam, S. T., Swanson, K. C., \& Vonnahme, K. A. (2018). Effects of maternal nutrient restriction followed by realimentation during early and mid-gestation in beef cows. II. Placental development, umbilical blood flow, and uterine blood flow responses to diet alterations. Theriogenology, 116, 1-11.

Du, M., Tong, J., Zhao, J., Underwood, K. R., Zhu, M., Ford, S. P., \& Nathanielsz, P. W. (2010). Fetal programming of skeletal muscle development in ruminant animals. Journal Animal Science, 88, 51-60.

Du, M., Huang, Y., Das, A. K., Yang, Q., Duarte, M. S., Modson, M. V., \& Zhu, M. J. (2013). Manipulating mesenchymal progenitor cell differentiation to optimize performance and carcass value of beef cattle. Journal Animal Science, 91(3), 1419-1427.

González-Recio, O., Ugarte, E., \& Bach, A. (2012). Trans-Generational Effect of Maternal Lactation during Pregnancy: A Holstein Cow Model. Plos One, $7(12), 1-7$.

Klein, J. L., Machado, D. S., Porsch, R. V., Brondani, I. L., Alves Filho, D. C., Moura, A. F., Cardoso, G. S., Silva, A. L., Domingues, C. C., \& Silva, M. A., (2018). Eficiência bionutricional e características da carcaça de novilhos confinados recebendo distintas fontes nitrogenadas com milho moído ou inteiro. Semina: Ciências Agrárias, 39(6), 2541-2554.

LeMaster, C. T., Taylor, R. K., Ricks, R. E., \& Long, N. M. (2017). The effects of late gestation maternal nutrient restriction whit or without protein supplementation on endocrine regulation of newborn and postnatal beef calves. Theriogenology, 87, 64-71.

Long, N. M., Vonnahme, K. A., Hess, B. W., Nathanielsz, P. W., \& Ford, S. P. (2009). Effects of early gestational undernutrition on fetal growth, organ development, and placentomal composition in the bovine. Journal of Animal Science, 87, 1950-1959.

Maresca, S., Lopes Valiente, S., Rodrigues, A. M., Long, N. M., Pavan, E., \& Quintans, G. (2018). Effect of protein restriction of bovine dams during late gestation on offspring postnatal growth, glucose-insulin metabolism and IGF-1 concentration. Livestock Science, 212, $120-126$.

Marques, R. S., Cooke, R. F., Rodrigues, M. C., Moriel, P., \& Bohnert, D. W. (2016). Impacts of cow body condition score during gestation on weaning performance of the offspring. Livestock Science, 191, 174-178.

McCarty, K. J., Washburn, J. L., Taylor, R. K., \& Long, N. M. (2020). The effects of early or mid-gestation nutrient restriction on bovine fetal pancreatic development. Domestic Animal Endocrinology, 70, 1-6.

Mohrhauser, D. A., Taylor, A. R., Underwood, K. R., Pritchard, R. H., Wertz-Lutz, A. E., \& Blair, D. A. (2015). The influence of maternal energy status during midgestation on beef offspring carcass characteristics and meat quality. Journal of Animal Science, 93, 786-793. 
Research, Society and Development, v. 10, n. 1, e39610111823, 2021

(CC BY 4.0) | ISSN 2525-3409 | DOI: http://dx.doi.org/10.33448/rsd-v10i1.11823

Reynolds, L. P., Borowicz, P. P., Caton, J. S., Crouse, M. S., Dahlen C. R., \& Ward, A. K. (2019). Developmental Programming of Fetal Growth and Development. Veterinary Clinics Food Animal, 35(2), 229-247.

Silveira, M. F., Restle, J., Alves Filho, D. C., Missio, R. L., Donicht, P. A. M. M., Segabinazzi, L. R., Callegaro, A. M., \& Joner, G. (2014). Suplementação com gordura protegida para vacas de corte desmamadas precocemente mantidas em pastagem natural. Arquivo Brasileiro de Medicina Veterinária e Zootecnia 66(3), 809-817.

Taylor, A. R., Mohrhauser, D. A., Pritchard, R. H., Underwood, K. R., Wertz-Lutz, A. E., \& Blair, D. A. (2016). The influence of maternal energy status during mid-gestation on growth, cattle performance, and the immune response in the resultant beef progeny. The Professional Animal Scientist, 32, 389-399.

Torres, H. A. L., Tineo, J. S. A., \& Raidan, F. S. S., (2015). Influência da condição corporal na probabilidade de prenhez de bovinos de corte. Archivos de Zootecnia, 64(247), 255-260.

Webb, M. J., Block, J. J., Funstons, R. N., Underwood, K. R., Legako, J. F., Harty, A. A., Slaverson, R. R., Olson, K. C., \& Blair, A. D. (2019). Influence of maternal protein restriction in primiparous heifers during mid and/or late-gestation on meat quality and fatty acid profile of progeny. Meat Science, 152, 31-37. 